\title{
Investigation of Ni-based SiC Thicker Coating by Induction Cladding
}

\author{
Deqin Sun, Yi Xu \\ School of Chemical \& Materials Engineering \\ Changshu Institute of Technology \\ Changshu, China
}

\author{
Guohong Dai \\ Jiangsu Key Laboratory of Recycling and Reuse \\ Technology for Mechanical and Electronic Products \\ Changshu, China
}

\author{
Zhengya Xu \\ Suzhou Key Laboratory of Intelligent Equipment Technology for ELV Recycling \\ Changshu, China
}

\begin{abstract}
Fabrication of thicker coating by induction cladding could achieve excellent properties, such as wear resistance, corrosion resistance, heat resistance and so on, and also was an important technology for machinery parts remanufacturing. Used the mixture of $\mathrm{Ni60}$ and $\mathrm{SiC}$ powder as coating materials, discussed the processing feasibility of preparing $\mathrm{SiC}$ coating on steel substrate by induction cladding. The optimum technological parameters by which can obtain good cladding quality were: $\mathrm{SiC}$ ratio is $20 \%$, sodium silicate as the binder, heated at $150{ }^{\circ} \mathrm{C}$ for 1 hours, intermitted heating with $\mathrm{Ar}$ gas protection, and achieved high quality $\mathrm{SiC}$ coating: the layer thickness was above $400 \mu \mathrm{m}$, coating hardness was about $750 \mathrm{HV}$, and achieved metallurgical bonding between the coating and steel substrate.
\end{abstract}

Keywords - induction cladding; SiC coating; coating capabilities; metallurgical bonding

\section{INTRODUCTION}

With the development of modern industrialization, the service performance of engineering equipments required more and more higher, and the machinery components, as the basic units of engineering equipments, were suffered more and more poor work environment. Preparing coating on the components to be repaired can achieve expected surface performances of abrasion resistance, corrosion resistance and other special properties, by reasonable design of the coating composition, and application of proper processing, and be benefit for improving material properties and prolonging the service life of all sorts of engineering components [1].

At present, research of functional coating materials focused on the cermets, which obtained ceramics properties, including excellent chemical stability, resistance to wear, corrosion, and high temperature, et al, meanwhile possessed the characteristic of the metal materials with high strength and toughness[2]. Nowadays, cermets coating materials, mainly including carbides, oxides, nitrides, borides and inter-metallic compounds, had been studied and applied in engineering[3]. There were two typical wear-resistant coating materials, one possessed the characteristic of high melting point and high hardness, mainly included some carbides and nitrides, such as WC, B4C, TiN etc [4]; Another was the cladding materials with low friction coefficient and self-lubrication, such as MoS2 [5]; Borides which had capabilities of high meltingpoint, high hardness, chemical stability, etc, often used as protective coating materials to achieve special performances of good thermal stability, wear resistance and corrosion resistance [6]; Pure oxides such as $\mathrm{ZrO} 2, \mathrm{Al} 2 \mathrm{O} 3, \mathrm{SiO} 2$, etc., or their composite were constantly used to prepare thermal barrier coatings. Among these, $\mathrm{ZrO} 2$ was most widely applied[7]. Meanwhile, the coating fabrication technology were rapidly developed, such as thermal spraying and spraywelding[8], laser cladding[9], sol-gel process[10], Vapor deposition[11], etc. But most of the processing equipments were more expensive, the cladding layers were usually thin, and the junction between the coating and substrate mostly showed the physical binding mode, resulted in the lower bonding strength. Therefore, all above technologies were not suitable for remanufacturing of engineering components, which needed enough coating thickness to recover its dimension or shape defects.

\section{MATERIALS AND EXPERIMENTAL METHODS}

Selected $\mathrm{SiC}$ powder as coated aggregates. SiC powder possessed excellent properties, such as density of $3.20 \sim 3.25 \mathrm{~g} / \mathrm{cm} 3$, melting point of about $2700^{\circ} \mathrm{C}$, micro hardness of $2840 \sim 3320 \mathrm{~kg} / \mathrm{mm} 2$, and had stable chemical properties, high thermal conductivity, low thermal expansion coefficient, good wear resistance and so on. Thus, using $\mathrm{SiC}$ powder for cladding could greatly improve the wear and corrosion resistance and other properties [8]. In order to make the $\mathrm{SiC}$ powder effectively consolidate on the surface of 45 steel substrate, Ni60 was used as a transition material, which improved to make the metallurgical reaction between the Ni60 alloy and the steel substrate [9].

Experimental procedures as follows: (1) surface pretreatment of steel substrate, including the elimination of surface rust, oil and other impurities, surface activation; (2) mixed the Ni60 and $\mathrm{SiC}$ powder materials to be welldistributed, and added proper proportion of the proportion of 
blinders to form the Viscous paste, then coated on the steel substrate; (3)Dried the coated specimens; (4) Placed the specimens in induction device, and heated to the molten state, stop heating; (5) took out the specimen and air-cooled to room temperature; (6) detected the coating performances.

Using high frequency induction equipment of TG-GP$100 \mathrm{KW}$ models to carry out the coating forming process, MiniTest740 coating thickness gauge to measure the coating thickness, optical microscopy or scanning electron microscopy (SEM) to analyze the microstructure, scanning electron microscope (SEM) to scan the interfacial chemical composition distribution, and TWV-1S type microaccelerometers to measure the surface hardness and interfacial hardness distribution.

\section{RESULTS AND DISCUSSION}

\section{A. Effect of SiC mass ratio}

Fig.1, 2 and 3 showed the bonding characteristics of the different $\mathrm{SiC}$ mass ratios which being respectively 10\%, 20\% and $30 \%$. The results showed that the bonding transition layer was all formed between the substrate and coating layer, and all achieved metallurgic bonding effects. Ni60 Alloy contains many metallic elements, such as $\mathrm{Ni}, \mathrm{Cr}, \mathrm{Fe}$, etc., which can solid dissolved in steel matrix, so these elements could diffuse into each other between Ni60 Alloy and 45 steel substrate when heated to higher temperature and kept a certain time, so created the metallurgical bonding, and obtained good bonding strength. But with the increase of the $\mathrm{SiC}$ mass ratio, the thickness of transition layer regions decreased. The principal reason was that, $\mathrm{SiC}$ powder had good chemical stability, and its numerously existence in Ni60 Alloy could prevent the diffusion of $\mathrm{Ni}, \mathrm{Cr}, \mathrm{Fe}$, etc.. Fig.4 showed the result that, the surface hardness increased with the increase of $\mathrm{SiC}$ powder mass ratio, and indicated that produced the particle-reinforced effect in the Ni60 alloy due to the existence of SiC particles with high hardness. Comprehensively considered the combination state and the coating performance, the best coating quality could be achieved when the $\mathrm{SiC}$ mass ratio was $20 \%$ in coating mixture.

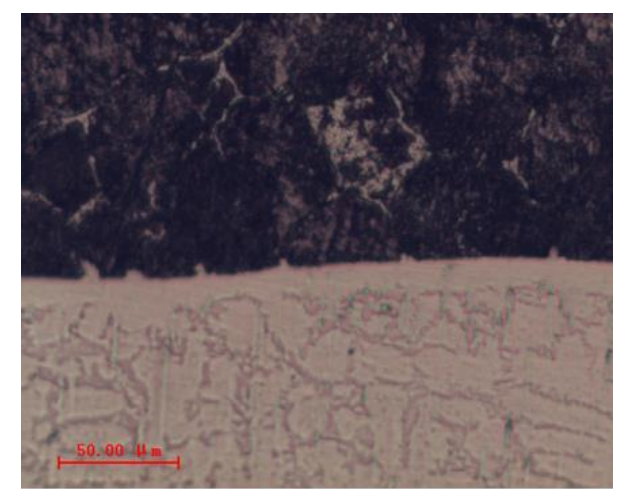

Fig. 1 bonding pattern of $10 \%$ SiC mass ratio

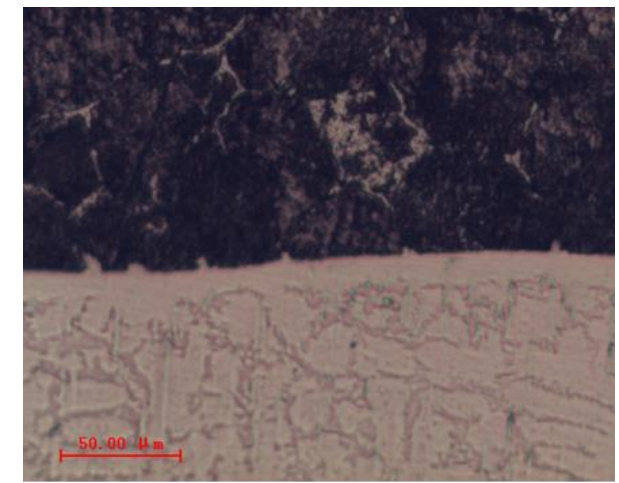

Fig. 2 bonding pattern of $20 \% \mathrm{SiC}$ mass ratio

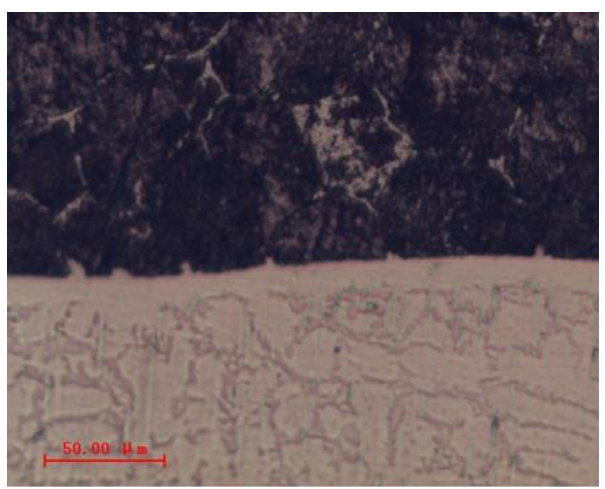

Fig. 3 bonding pattern of $30 \% \mathrm{SiC}$ mass ratio

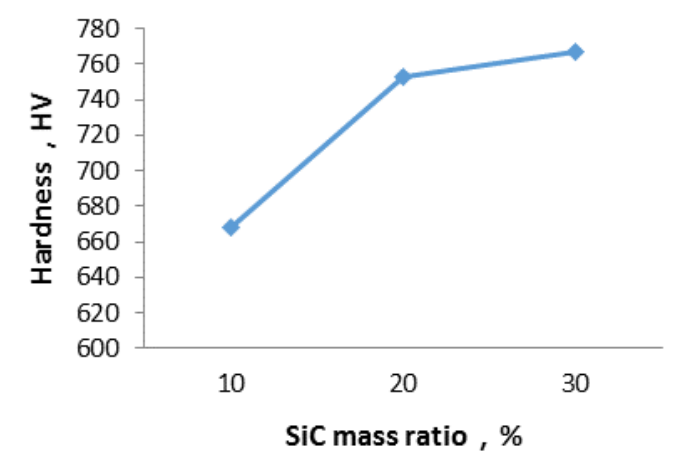

Fig. 4 surface hardness of different $\mathrm{SiC}$ mass ratio

\section{B. Effect of binder types}

Fig. 5 and Fig. 6 respectively illustrated the bonding morphology of the samples which was prepared when using turpentine (mixed rosin and Turpentine together in the mass ratio of 1:3) and sodium silicate as binder. The metallurgical bonding can be obtained by using sodium silicate as binder, as shown in Fig.5; whereas obvious dividing boundary occurred between the coating and substrate when using turpentine as binder, as shown in Fig.6. Turpentine was organic compound, and easy to produce large amounts of gas when being heated. Thus easily produced a certain air gap in the interface, and cut off the connection between coating and substrate. Accordingly, even though in a highly heated state, the diffusion of elements could not effectively carry out, and difficult to achieve the metallurgical bonding effect. In the experimental process, 
found that the bulging was frequently happened, and some white smoke was also emerged in the course of induction heating. But using sodium silicate which was inorganic compound and with low moisture content, as binder seldom evaporated the moisture, thus could maintain the close contact between coating and substrate in the process of induction cladding, better for the elements diffusion of $\mathrm{Ni}, \mathrm{Fe}$, and easily achieved good metallurgical combination.

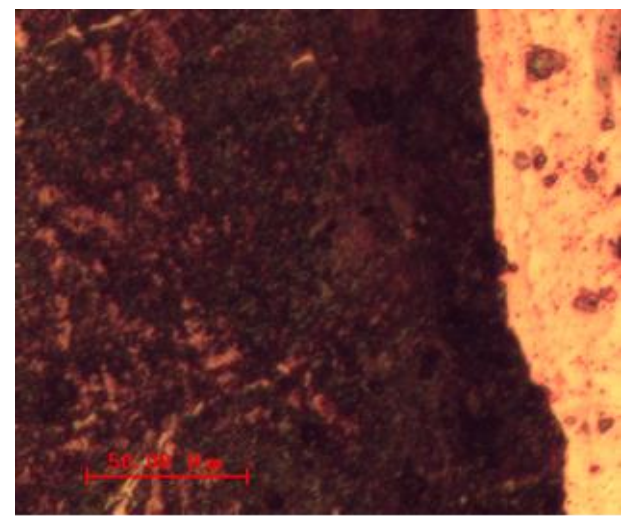

Fig. 5 bonding pattern of sodium silicate as binder

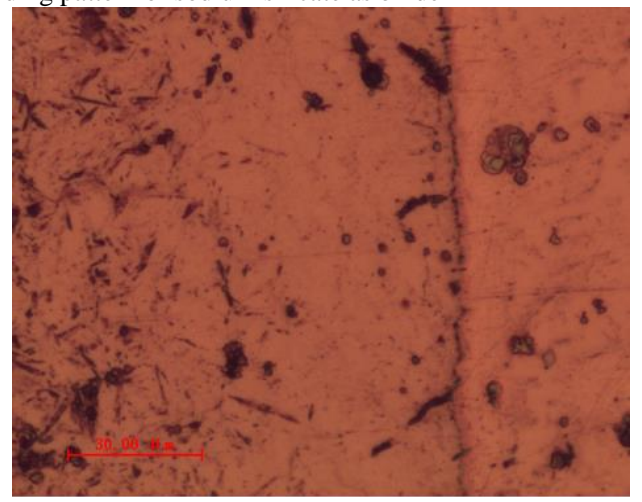

Fig. 6 bonding pattern of turpentine as binder

\section{Effect of coating drying methods}

The effect on the cladding quality of coating drying methods, including air dried and preheating at $150{ }^{\circ} \mathrm{C}$ for 60 min, was also important. As illustrated in Fig.7, a distinct boundary existed in the joint region between the coating and substrate, proved that no obvious transition layer was produced in processing of air-dried at room temperature. For the air dried process, the drying procedure began from the outer surface, thus the moister existed nearby the coatingmatrix interface was difficult to escape out, easier to form a air gap in the subsequent induction heating, thus contributed to the lack of elements diffusion between the coating and the substrate. Whereas for the preheating-drying process, internal moister existed in coating mixture could escape out in a steady flow, and the moister emissions could be carried out completely. But if the temperature was above $200^{\circ} \mathrm{C}$, surface bulging was obvious produced due to the excessive gas escaping current, even caused the coating materials falling off. Proved by experiments that, achieved excellent bonding patterns when preheated at $150^{\circ} \mathrm{C}$ for $60 \mathrm{~min}$, and formed a clear transition region, as schematic in Fig. 8.

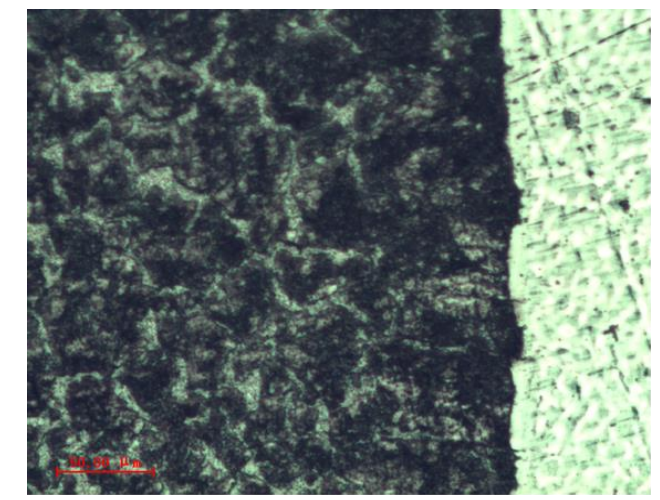

Fig.7 morphology of air dry for 24 hours

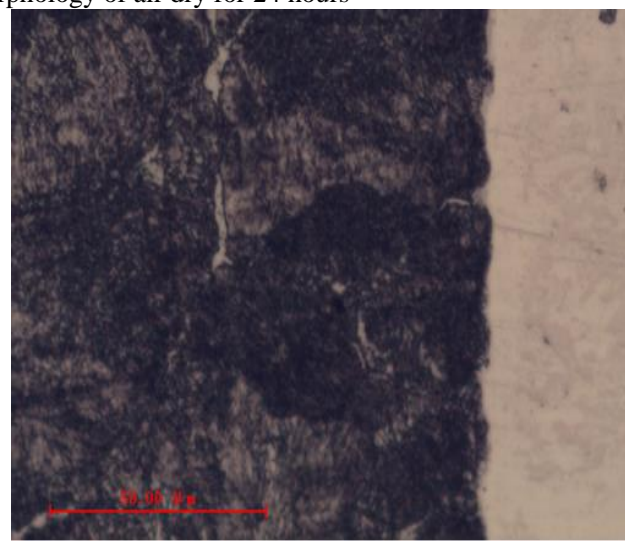

Fig. 8 morphology of $150^{\circ} \mathrm{C}$ preheating for $60 \mathrm{~min}$

\section{Effect of induction heated methods}

The effect of the heating parameters in the induction cladding process on the coating quality was obvious. Fig. 9 described the changing of the coating thickness obtained by three different heating procedures : (1) continuous heating in a constant current; (2) intermittent heating process which heated for $2 \mathrm{~s}$ in a certain current, stopped heating for $5 \mathrm{~s}$ or so, then reheating again, until occurred molted state on the surface; (3) intermittent heating with argon protection. For continuous heating process, because of the strong heating intensity, the internal residual moisture would be vaporized and expanded rapidly, caused the coating materials falling off from the sample surface, so the coating thickness is smaller. As for the intermittent heating, the intensity of heating were declined, the residual moisture could escape slowly; Meanwhile in the intermittent heating process, the relative high temperature state on the sample surface would stay for a longer time, the elements diffusion between the coating materials and substrate carried out more adequately, so the coating thickness was increased greatly; Adding the argon protection measures for the intermittent heating process avoided the oxidizing reaction of the coating material, and more effectively prevented the coating powder materials fall off, so the coating thickness still raised up; thus, formed excellent metallurgical bonding, and basically eliminated the oxidation inclusions within the transition layer, as shown in figure 10. 


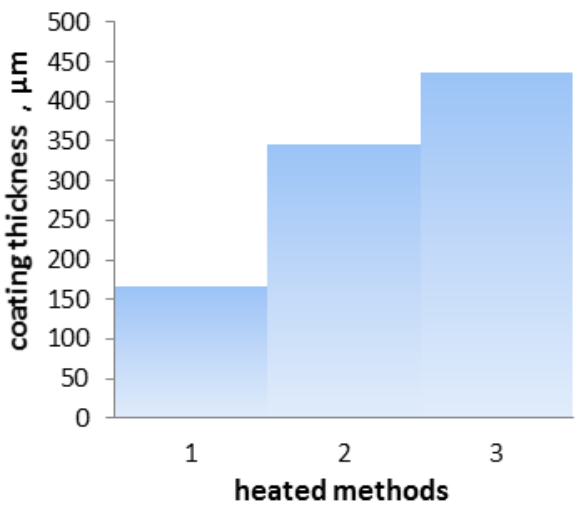

Fig. 9 comparison of coating thickness. 1-continous heated; 2- intermittent heating; 3-intermittent heating with argon protection.

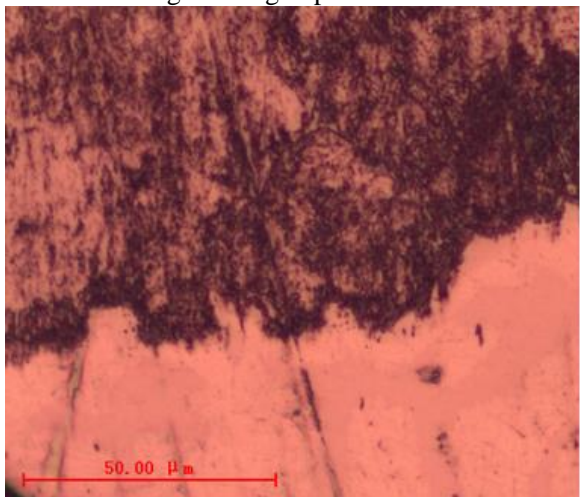

Fig. 10 morphology of intermittent heating with argon gas

\section{E. Optimized process parameters and the cladding quality}

Through large amounts of experiments, achieved the comparatively ideal processing parameters of getting desired cladding quality, including: (1) $\mathrm{SiC}$ mass ratio was $20 \%$ in composite coating material; (2) used sodium silicate as binder;(3) preheated at $150^{\circ} \mathrm{C}$ for 60 minutes to remove the internal moister; (4) induction heated in intermittent heating style with the aid of argon protection.

1) Cladding process had little effect on the substrate microstructure

Fig. 11 showed the original microstructure of the 45 steel substrate, and the morphology of the substrate after cladding process as schematic in Fig.12. Compared Fig.11 and Fig.12, the ferrite and pearlite grains basically remain unchanged after induction cladding process, and resulted little damage to the substrate. This dues to the very short time of induction heating, and the heating energy was concentrated on the surface thinner layer.

\section{2) Displayed clear metallurgical bonding features}

Fig.13 showed the microstructure of the junction area. Compact structure and fine grains existed in the cladding layer, and the distribution of $\mathrm{SiC}$ particles is uniformity; produced a clear transition layer, which produced by elements diffusion of $\mathrm{Fe}, \mathrm{Ni}$ and so on. The component scanning curves represented that, both $\mathrm{Fe}$ and $\mathrm{Ni}$ elements expressed the features of transitional changes in the bonding area, as shown in Fig.14; The results of hardness testing also reflected the transitional features of mechanical properties, as shown in Fig.15. These results indicated that excellent metallurgical bonding was produced, and achieved formed closely integrated and fined microstructure.

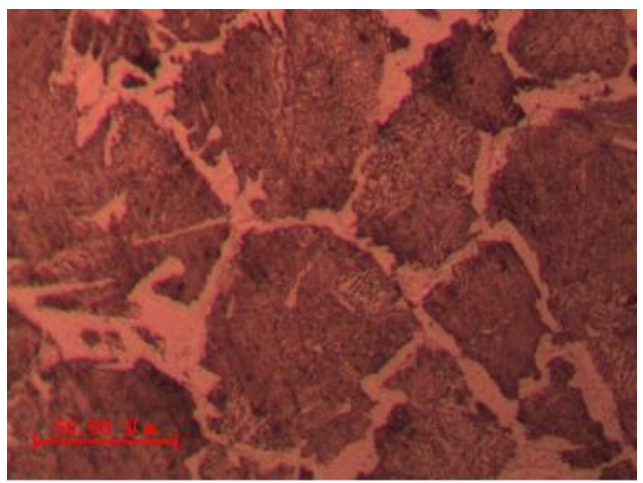

Fig. 11 microstructure of the primary substrate

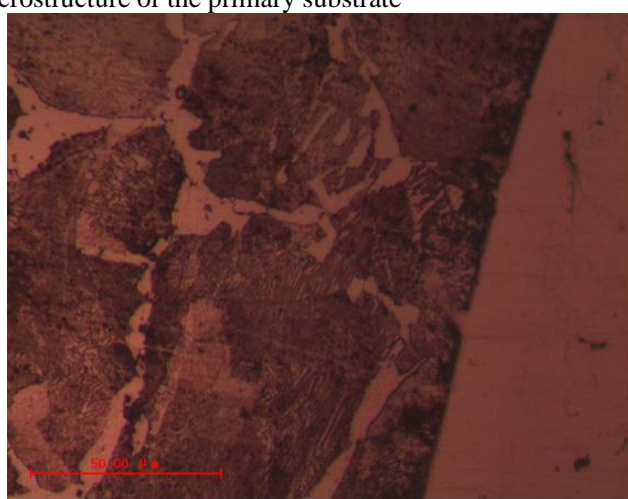

Fig. 12 microstructure of the substrate after coating

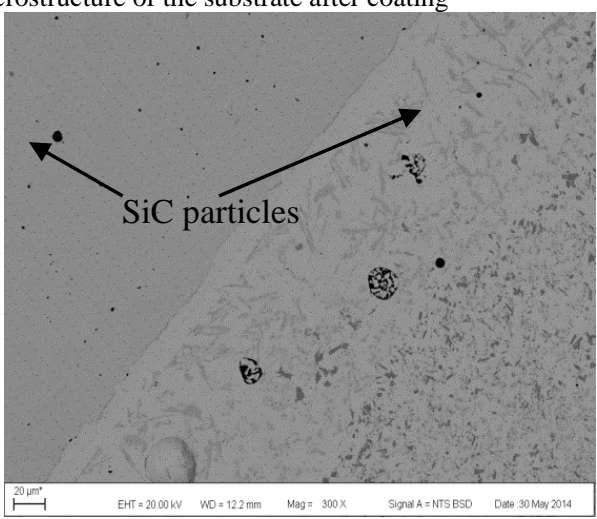

Fig. 13 microstructure of the transition layer

\section{3) achieved the desired performances}

The thickness of the cladding layer could reach over $400 \mu \mathrm{m}$, and basically maintained technological requirements of engineering components repairing and remanufacturing process; The hardness in cladding layer could be up to 750 $\mathrm{HV}$, and afford good wear resistance for the repaired material surface; Corrosion testing of 5\% hydrochloric acid for 8 hours also proved that, the formation of $\mathrm{SiC}$ coating greatly improved the corrosion resistance of substrate materials, as shown in Fig. 16. 


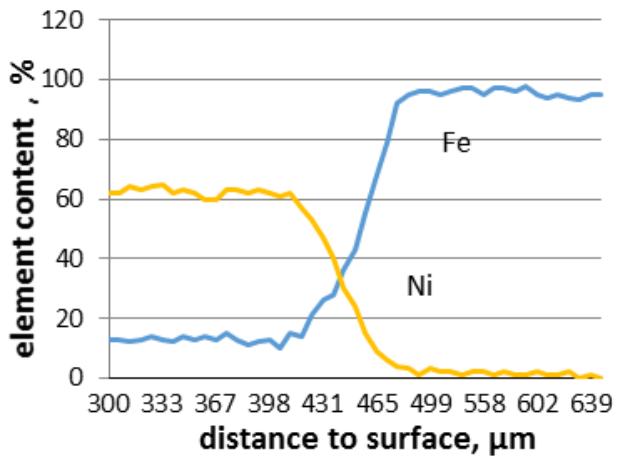

Fig. 14 component scanning curves of Fe and Ni elements

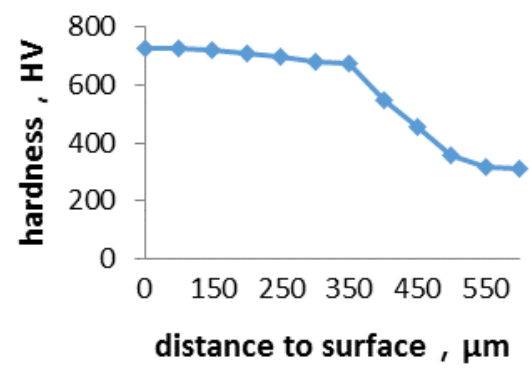

Fig. 15 curve of hardness variation along radius

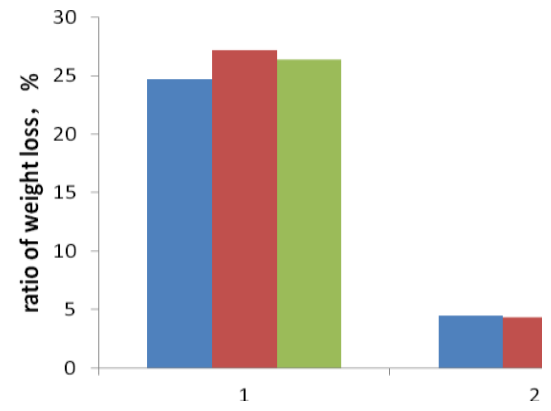

Fig. 16 comparison of weight loss in corrosion experiment. 1-Non-coating sample; 2- sample with coating

\section{CONCLUSIONS}

Carried out feasible research on the technology of $\mathrm{Ni}$ based $\mathrm{SiC}$ coating preparation by induction cladding process, and drawn the following conclusions:

(1) The best technological condition of $\mathrm{Ni}$ based $\mathrm{SiC}$ coating preparation was that: $\mathrm{SiC}$ mass ratio in the coating material was $20 \%$; using sodium silicate as binder; well mixed $\mathrm{Ni60}$ and $\mathrm{SiC}$ powder to be a paste fluid, then coated on the substrates; preheated at $150^{\circ} \mathrm{C}$ for 60 minutes; heated in intermittent induction heating style with the aid of argon protection, stopped the heating process until the surface melting signs appeared, air cooled to the room temperature.

(2) achieved excellent metallurgical bonding; the surface hardness reached HV750, the coating thickness was above $400 \mu \mathrm{m}$; improved the properties of corrosion resistance.

\section{REFERENCES}

[1] G. Eason, B. Noble, and I.N. Sneddon, "On certain integrals of Lipschitz-Hankel type involving products of Bessel functions," Phil. Trans. Roy. Soc. London, vol. A247, pp. 529-551, April 1955. (references)

[2] J. Clerk Maxwell, A Treatise on Electricity and Magnetism, 3rd ed., vol. 2. Oxford: Clarendon, 1892, pp.68-73.

[3] I.S. Jacobs and C.P. Bean, "Fine particles, thin films and exchange anisotropy," in Magnetism, vol. III, G.T. Rado and H. Suhl, Eds. New York: Academic, 1963, pp. 271-350.

[4] K. Elissa, "Title of paper if known," unpublished.

[5] R. Nicole, "Title of paper with only first word capitalized," J. Name Stand. Abbrev., in press.

[6] Y. Yorozu, M. Hirano, K. Oka, and Y. Tagawa, "Electron spectroscopy studies on magneto-optical media and plastic substrate interface," IEEE Transl. J. Magn. Japan, vol. 2, pp. 740-741, August 1987 [Digests 9th Annual Conf. Magnetics Japan, p. 301, 1982].

[7] M. Young, The Technical Writer's Handbook. Mill Valley, CA: University Science, 1989. 